\title{
Effectiveness of topiramate for tobacco dependence in patients with depression; a randomised, controlled trial
} Javier García Campayo*1, Natalia Sobradiel 1,7, Marta Alda ${ }^{2,7}$, Adoración Mas ${ }^{3,7}$, Eva Andrés ${ }^{1,7}$, Rosa Magallón ${ }^{4,7}$, Arantxa Crucelaegui ${ }^{5,7}$ and Beatriz Sanz ${ }^{6,7}$

Address: ${ }^{1}$ Servicio de Psiquiatría, Hospital Miguel Servet y Universidad de Zaragoza, Spain, ${ }^{2}$ Servicio de Psiquiatría. Hospital de Alcañiz, Teruel, Spain, ${ }^{3}$ Centro de Salud Perpetuo Socorro, Huesca, Spain, ${ }^{4}$ Centro de Salud Arrabal, Zaragoza, Spain, ${ }^{5}$ Servicio de Urgencias. Hospital de Tudela, Navarra, Spain, ${ }^{6}$ Hospital de la Defensa, Zaragoza, Spain and ${ }^{7}$ Grupo Aragonés de Investigación en Atención Primaria. Red de Actividades Preventivas y de Promoción de la Salud (REDIAPP) (G03/170). Instituto Aragonés de Ciencias de la Salud (IACS)

Email: Javier García Campayo* - jgarcamp@arrakis.es; Natalia Sobradiel - nsobradiel@ hotmail.com; Marta Alda - martaalda@hotmail.com; Adoración Mas - amas@comz.es; Eva Andrés - eandres@unizar.es; Rosa Magallón - med000764@gmail.com; Arantxa Crucelaegui - arantxa.cc@auna.com; Beatriz Sanz - felixm@able.es

* Corresponding author

Published: 7 May 2008

BMC Family Practice 2008, 9:28 doi:10.1 186/I47|-2296-9-28
Received: 4 March 2008

Accepted: 7 May 2008

This article is available from: http://www.biomedcentral.com/I47/-2296/9/28

(c) 2008 Campayo et al; licensee BioMed Central Ltd.

This is an Open Access article distributed under the terms of the Creative Commons Attribution License (http://creativecommons.org/licenses/by/2.0), which permits unrestricted use, distribution, and reproduction in any medium, provided the original work is properly cited.

\begin{abstract}
Background: Tobacco dependence management is a multi-component intervention that includes pharmacological treatments such as Nicotine Substitution Therapy (NST) or bupropion, and psychological therapy. There are some preliminary reports on topiramate efficacy for tobacco dependence. The aim of this study is to determine whether topiramate is as effective as the standard NST treatment for tobacco cessation at I-year follow-up in patients with depression.
\end{abstract}

Method/design: Design: A randomised, controlled trial involving two groups, one of which is the control group consisting of patients on the standard pharmacological treatment for tobacco cessation (NST) and the other is the intervention group consisting of patients on topiramate as pharmacological treatment.

Setting: 29 primary care health centres in the city of Zaragoza, Spain.

Sample: 180 patients, aged 18-65 years, diagnosed with major depression, smoke more than 20 cigarettes/day, who have voluntarily asked for tobacco cessation therapy.

Intervention: A multi-component programme for tobacco cessation is offered to all of the patients in the study. This programme is made up of pharmacological therapy + group cognitive-behavioural therapy. Pharmacological therapy consists of NST for the control group and topiramate $(200 \mathrm{mg} /$ day) for the intervention group. Psychological therapy is made up of 16 sessions of manualised group therapy.

Measurements: Cessation will be assessed by patient self-declared abstinence, expired air carbon monoxide levels, and cotinine levels in saliva. Questionnaires on tobacco dependence, anxiety, depression, impulsiveness and self-efficacy will be administered. The interviewers will not know which group the patient belongs to (blind). The assessments will be carried out at baseline, D (cessation day) -I, D+I, weeks I, 2, 3, 4, 6, 8, 10 and I3, and months 4, 5, 6, 8, 10 and 12 . 
Main variables: Tobacco cessation rates and tobacco dependence.

Analysis: The analysis will be per intent to treat. We will use the general linear models of the SPSS version 15 statistical package, to analyse the effect of the treatment on the result variable (tobacco cessation rate).

Discussion: It is necessary to develop new and more effective pharmacological treatments for tobacco cessation. This randomised clinical trial will determine whether topiramate is effective for tobacco cessation in patients with depression.

Trial registration: Current Controlled Trials ISRCTN9353208I

\section{Background}

Tobacco abuse is the main avoidable cause of death and disability in the world that is unrelated to others. The World Health Organization (WHO) estimates that 4 million persons died of tobacco-related disorders in 2002 [1]. In Spain, the latest available data from the National Health Survey (Encuesta Nacional de Salud) in 2003 [2] describe a prevalence of tobacco consumption of $31 \%$, with a decrease in consumption by males, and a small but significant increase in consumption by females, mainly in adolescents and young women. For these reasons tobacco use is considered a public health problem and its treatment constitutes a challenge for health services.

At present, tobacco dependence management is carried out in a collaborative way in primary care and specialised settings by means of treatments that range from minimal to intensive intervention [3]. In the latter, a multi-component cessation intervention is applied by health professional specialised in tobacco dependence management $[4,5]$. The multi-component intervention includes firstline pharmacological treatments for tobacco such as Nicotine Substitution Therapy (NST) or bupropion, and psychological treatments. This intervention obtains a remission rate of $30-40 \%$ at 1 -year follow-up $[5,6]$. As psychological therapy, cognitive-behavioural interventions, which can be administered on a group or individual basis, are used with follow-up sessions during the first year of abstinence. NST is administered by transdermal patches as basal treatment [7-9], added to nicotine lozenges [10] or nicotine chewing gums [11] that are selfadministered occasionally depending on abstinence symptoms. Bupropion is a noradrenergic and dopaminergic antidepressant used for tobacco dependence because it acts on nicotinic receptors. It is twice as effective as a placebo for this treatment [12]. However, in psychiatric patients it should be used with caution owing to potential interactions with CYP2D6, an enzyme involved in the metabolisation of many psychiatric drugs [13].

Topiramate seems to be a new and promising pharmacological treatment for tobacco. A new antiepileptic drug, it was originally designed as an oral hypoglycaemic, and was subsequently approved as an anticonvulsant. It has increasingly been used in the treatment of numerous psychiatric conditions (binge eating disorders, bulimia nervosa, and alcohol dependence) and it has also been associated with weight loss, potentially relevant in reversing weight gain induced by psychotropic medications [14]. Topiramate has demonstrated its efficacy for the treatment of alcohol dependence in randomised controlled trials [15]. There are also some preliminary reports of its effectiveness for the treatment of tobacco dependence, despite these reports being substudies of other trials on alcohol dependence [16], uncontrolled studies with small samples [17] or short-term studies [18].

Recently, a group of smokers have been described as "special populations". These are groups with certain characteristics that require the need for more intensive treatments to attain tobacco cessation, owing to limitations in the use of pharmacological treatments (pregnancy) or because the cessation must be more immediate (patients with heart disorders or emphysema) [4]. One of these special populations is psychiatric patients in whom prevalence of tobacco dependence is higher than in the general population (52\% vs. 31\%) and effectiveness of cessation programmes are less effective [19]. In persons who smoke, there is a direct relationship between severity of psychiatric symptoms and tobacco dependence [20]. Specifically, patients with depression show more likelihood to become heavy smokers, to have more difficulties in stopping smoking, and to suffer from more abstinence symptoms than general population [21]. At present, there are not enough research studies on the effectiveness of topiramate for tobacco cessation and, specifically, in psychiatric populations such as patients with depression.

\section{Methods/Design Objectives}

The general aim is to determine whether topiramate is at least as effective as NST in tobacco cessation at 1-year follow-up in patients with depression. The specific aims are to determine the factors that predict a good response to topiramate treatment and the possible differences in effectiveness in relation to gender. 


\section{Design}

This is a controlled trial with a random allocation of patients into two alternative branches (see Figure 1):

1. Tobacco cessation standard treatment with NST (control group) and

2. Tobacco cessation treatment with topiramate (intervention group).

The evaluation of the treatment outcomes will be performed at patient level and they will be assessed individually.

\section{Setting and study sample}

Patients will be recruited from any of the 29 primary health care centres in the city of Zaragoza (Aragonese
Health Service), Spain. Patients will be recruited by doctors working in these primary care centres until the required sample is completed, without a quota of patients assigned for every centre.

Patients considered for inclusion are those aged 18-65 years, able to understand and read Spanish, who fulfil criteria for major depression (DSM-IV criteria), with scores on the Zung Self-Rating Depression Scale < 60 [22] (implying minimal to mild depression), who smoke more than 20 cigarettes/day, fulfil preparation state of change according to Prochaska \& DiClemente [23], voluntarily ask for a tobacco cessation therapy, and sign informed consent. Those excluded will be patients with active psychosis and/or treatment with antipsychotic drugs, alcohol or drug abuse, and pregnancy or lactation.

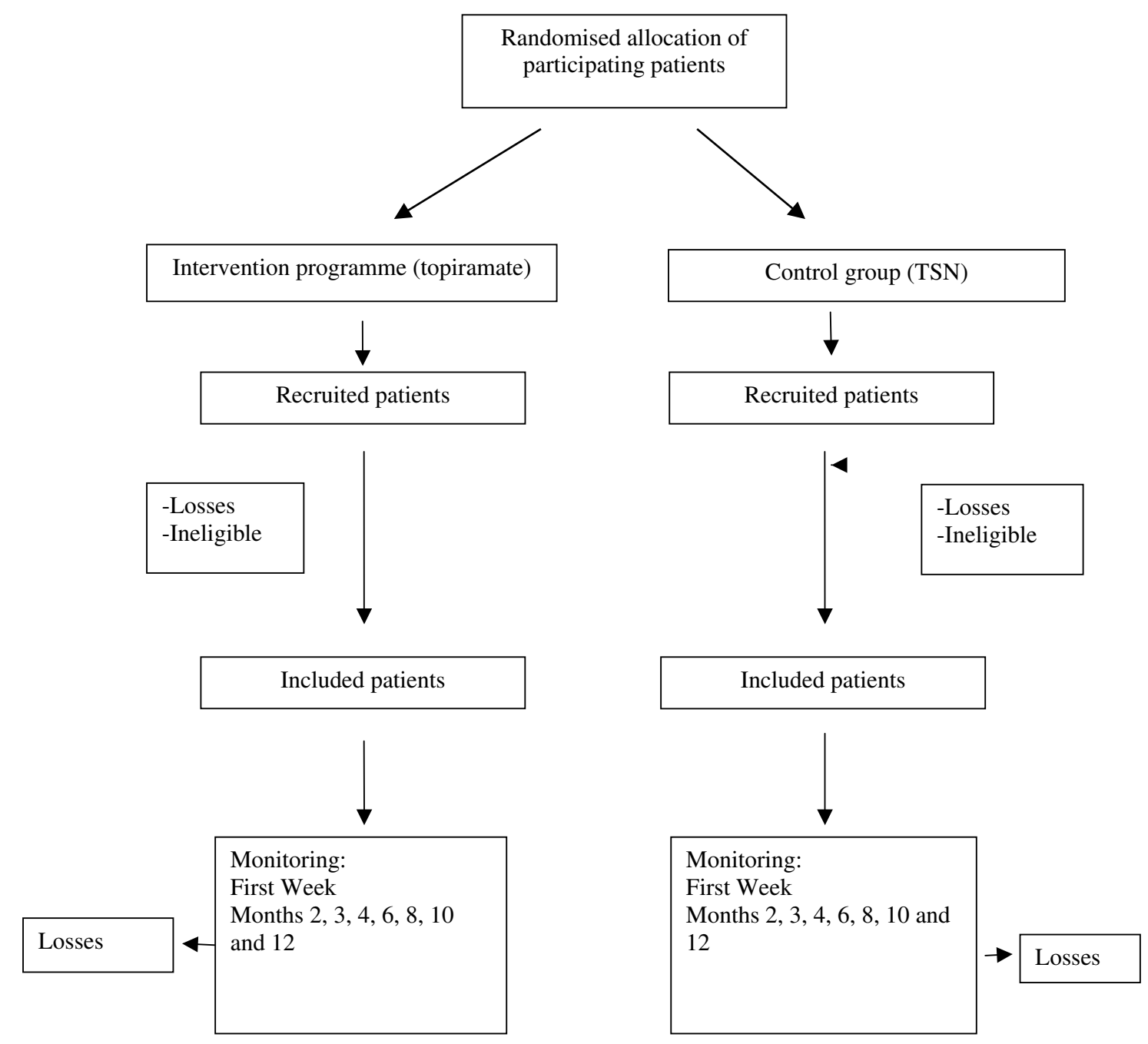

Figure I

Flowchart: randomisation, sampling and monitoring of patients. 


\section{Randomisation, allocation and masking of study groups} Each patient will be allocated to either the intervention or the control group using a computer-generated random number sequence. The allocation will be carried out by an independent person, belonging to REDIAPP (Research Network on Preventative Activities and Health Promotion), who is not involved in the study. The method used to implement the random allocation sequence will be a central telephone. The sequence will be concealed until interventions are assigned. Patients agree to participate before the random allocation and without knowing which treatment they will be allocated to. Pharmacological treatment will be administered by a psychiatrist (JGC). Study personnel conducting psychological intervention and assessments (NS, AM, AC) will be masked to participants' treatment conditions.

\section{Intervention}

Psychological intervention in both groups

A multi-component programme for tobacco cessation is offered to all of the patients in the study. This is made up of pharmacological therapy + group cognitive-behavioural therapy. The group is made up of 7-12 patients with depression and tobacco dependence, and is led by 2 therapists (a psychologist and a family doctor) trained in group therapy and tobacco cessation. Each session lasts 90 min., and the structure of every session and the contents are manualised and based on the standard programmes of this type [19]. It consists of 16 follow-up sessions: D (cessation day) $-1, \mathrm{D}+1$, weeks $1,2,3,4,6,8,10$ and 13, and months $4,5,6,8,10$ and 12 . Patients will be offered a phone number on which study personnel can solve problems and answer queries in relation to psychological (NS, AM) or pharmacological treatment (JGC).

\section{Pharmacological intervention}

Intervention group

In this group of patients, topiramate at doses used for the treatment of addictions (100-200 mg/day) will be administered [15-17].

\section{Control group (standard treatment)}

In this group, NST (nicotine patches) at usual doses (21 $\mathrm{mg} /$ day first and second fortnight, $14 \mathrm{mg} /$ day third fortnight and $7 \mathrm{mg} /$ day fourth and last fortnight), will be offered.

Pharmacological treatments will be financed by the grant. It will be administered by a psychiatrist (JGC). Duration of treatment, in both groups, will be 8 weeks. All patients will have free use of nicotine gums or lozenges during the two months of the treatment.

\section{Measurements}

The study personnel that carried out the measurements (NS, AM, AC) will be unaware of which pharmacological treatment the patients is being administered ("blind"). The follow-up assessments will take place at baseline (clinical interview), D -1, D + 1, weeks $1,2,3,4,6,8,10$ and 13 , and months $4,5,6,8,10$ and 12 .

Table I: Study variables

\begin{tabular}{|c|c|c|c|}
\hline Instrument & Assessment area & Applied by & Time(s) of assessments \\
\hline Sampling form & Age, sex, inclusion/exclusion criteria & Family doctor & Baseline \\
\hline Sociodemographic data form & $\begin{array}{l}\text { Age, sex, marital status, educational } \\
\text { level, Socio-economic group ( } 28) \text {, } \\
\text { occupation }\end{array}$ & Research assistant & Baseline \\
\hline $\begin{array}{l}\text { MINI psychiatric interview, depression } \\
\text { and tobacco dependence modules (27) }\end{array}$ & Psychiatric diagnosis & Research psychiatrist & Baseline \\
\hline Zung Self-Rating Depression Scale (22) & Severity of depression & Research assistant & Baseline and possible relapses \\
\hline State of change (23) & State of change & Research assistant & Baseline \\
\hline Self-declared abstinence & Tobacco abstinence & Research assistant & Baseline and all follow-up sessions* \\
\hline $\begin{array}{l}\text { Minnesota tobacco abstinence } \\
\text { symptoms (24) }\end{array}$ & Tobacco abstinence & Research assistant & Baseline and all follow-up sessions* \\
\hline $\begin{array}{l}\text { Expired air carbon monoxide levels } \\
(25)\end{array}$ & Tobacco abstinence & Research assistant & Baseline and all follow-up sessions* \\
\hline Cotinine levels in saliva & Tobacco abstinence & Research assistant & Baseline and all follow-up sessions* \\
\hline $\begin{array}{l}\text { Fagerström test for Nicotine } \\
\text { Dependence (29) }\end{array}$ & Tobacco dependence & Research assistant & Baseline and many follow-up sessions** \\
\hline $\begin{array}{l}\text { State-Trait Anxiety Inventory (STAI) } \\
\text { (30) }\end{array}$ & Anxiety & Research assistant & Baseline and many follow-up sessions** \\
\hline Plutchik Impulsivity Scale (3I) & Impulsivity & Research assistant & Baseline and many follow-up sessions** \\
\hline Visual analog scale & Efficacy self-perception & Research assistant & Baseline and many follow-up sessions** \\
\hline Medical record & Pharmacological side-effect events & Research assistant & Baseline and many follow-up sessions** \\
\hline
\end{tabular}

*All follow-up sessions: $D$ (cessation day) -I, D + I, weeks I, 2, 3, 4, 6, 8, 10 and I3, and months 4, 5, 6, 8, I0 and I2 (I6 sessions in total) **Many follow-up sessions: weeks I, 4, 8 and months $4,6,8,10,12$. 
Variables and instruments of measurement (See Table I) Main outcome variables

In accordance with the aims of the study, the major outcome is tobacco cessation in patients with depression. The diagnosis of tobacco dependence will be made with the Spanish version of the MINI psychiatric interview substance dependence module adapted to tobacco [24]. This modification has been validated on a Spanish population with adequate psychometric properties [19]. Tobacco abstinence will be diagnosed by self-declared abstinence, self-administered Minnesota tobacco abstinence symptoms [25], expired air carbon monoxide [26], and cotinine in saliva. Tobacco abstinence, according to majoritarily-accepted criteria [27], has been defined using 2 concepts: 1 . Occasional abstinence: In a follow-up visit, patients affirm that they have been abstinent, their levels of expired air carbon monoxide $<10 \mathrm{ppm}$, and cotinine levels in saliva $<5 \mathrm{ng} / \mathrm{ml}$. Continuous abstinence: As of the visit at 30 days, patients affirm that they were abstinent the month before, expired air carbon monoxide levels $<10 \mathrm{ppm}$ and cotinine levels in saliva $<5 \mathrm{ng} / \mathrm{ml}$. Tobacco relapse will be diagnosed with the MINI psychiatric interview substance dependence module adapted to tobacco [24].

The diagnosis of depressive disorder will be made with the Spanish version of the MINI psychiatric interview, depression module [24], and the severity of the depression with the Spanish version of the Zung Self-Rating Depression Scale [22]. Recruitment will only include patients with depressive disorder and Zung scale scores $<60$, which implies minimal to mild depression [22]. MINI psychiatric interview depression module [24], will be also used as criteria for depression relapse.

\section{Secondary variables}

-The following socio-demographic data will be collected: sex, age, marital status (single, married/relationship, separated/divorced, and widowed), education (no studies, primary, lower secondary, upper secondary, university), occupation and social class (I, II, IIIN, IIIM, IV and V of the British Registrar General's Scale) [28].

-Tobacco dependence as measured by the Spanish version of the Fagerström test for Nicotine Dependence [29].

-Anxiety trait and state as measured by the Spanish version of the State-Trait Anxiety Inventory (STAI) [30].

-Impulsivity as measured by the Spanish version of the Plutchik Impulsivity Scale [31].

-Visual analogue scale for efficacy self-perception (range 0-10).
-Pharmacological side-effect events from the medical record.

\section{Statistical methods}

Sample size

To calculate the sample size we consider the tobacco cessation rate at 1 year follow-up as the main outcome variable. On the basis of published research data [5,6], we assume that this will be $35 \%$ in the control (NST) group, and we aim to detect a difference of $25 \%$ or more between any of the two groups (control and intervention). Published studies place placebo response at 10\% [32]. Accepting an alpha risk of 0.05 and a beta risk of $<0.20$ in a bilateral contrast, we would need 90 patients in each group [33].

\section{Analysis strategy}

The analysis will be per intent to treat. First we will compare the intervention group with the control group in order to verify that there are no significant differences between the two groups (socio-demographic characteristics, clinical baseline data, etc). We will use the mean (standard deviation) in the continuous variables and percentages in the categorical variables. For comparisons we will use the Student-t test for continuous variables and the Chi-squared test for categorical variables. Non-parametric tests may also be used.

The main variables of the result are the percentage of patients with tobacco cessation (patient's self-declared abstinence, expired air carbon monoxide levels, selfadministered Minnesota tobacco abstinence symptoms, and cotinine levels in saliva), and tobacco dependence (Fagerström test for Nicotine Dependence scoring) at 1year.

Process variables include severity of the depression (Zung Self-Rating Depression Scale), anxiety trait and state (STAI), impulsivity (Plutchik Impulsivity Scale), and efficacy self-perception (visual analogue scale).

We will use the general linear models of the SPSS 15 statistical package, to analyse the effect of the treatment on the categorical result variables (tobacco cessation rate). We will use the analyses of linear mixed models to analyse the effect of the continuous process variables (depression, anxiety, impulsivity and efficacy).

\section{Ethical aspects}

Informed consent will be obtained from the participants before they are aware of which group they are to be included in. Before they give their consent, the patients will be provided with a general overview of the aims and characteristics of the study and the multi-component intervention. They will also be informed that they will be 
participating voluntarily, and that they can choose to withdraw at any time with the guarantee that they will continue to receive the treatment considered most appropriate by their doctor.

The study follows Helsinki Convention norms and posterior modifications and the Declaration of Madrid of the World Psychiatric Association. The Study Protocol was approved by the Ethical Review Board of the regional health authority in February 2007 (ref: FIS PI06/1462).

\section{Forecast execution dates}

Initial recruitment of patients: March 2008

Finalisation of patient recruitment: December 2008

Finalisation of patient monitoring period: December 2009

Publication of results: June 2010

\section{Discussion}

Effectiveness of multi-component programmes with standard pharmacological treatments (NST) for tobacco cessation in the general population is still unsatisfactory, with cessation rates at 1 -year follow-up ranging from $30-$ $40 \%[5,6]$. These rates are even less successful in special populations such as psychiatric patients [19]. For these reasons, it seems necessary to develop new and more effective pharmacological treatments. One of the most promising treatments is topiramate because it has demonstrated effectiveness on tobacco cessation in preliminary studies [16-18], and it is useful in many psychiatric conditions [14].

The strength of the study is that, to our knowledge, this is the first randomised, controlled trial of topiramate for tobacco cessation, with the standard treatment (NST) as comparator. The psychological intervention of the multicomponent programme is the usual group cognitivebehavioural therapy used in these programmes [19]. In addition, the modulator role of some important variables (such as anxiety, impulsivity, state of change, self-efficacy) in patients with depression has also been assessed.

A number of potential limitations may be difficulties in recruitment, due to lack of motivation for tobacco cessation in psychiatric patients, and the low cessation rate in this population making it difficult to interpret the results. The concept of states of change has also been criticised, so its utility may be doubtful.

\section{Competing interests}

The authors declare that they have no competing interests.

\section{Authors' contributions}

JGC is the principal researcher and developed the original idea for the study. The study design was further developed by MA, NS and RM. NS, AM, AC and BS participated in the design and planning of the intervention that is evaluated here. EA developed the statistical methods. All authors have read and corrected draft versions and approved the final version.

\section{Acknowledgements}

The study will be funded by a grant from the Carlos III Health Institute of the Spanish Ministry of Health and Consumption (FIS ${ }^{\circ}$ PI06/1462). We thank "Red de Investigación en Actividades de Prevención y Promoción de la Salud" (Research Network on Preventative Activities and Health Promotion) (REDIAPP-G03-170), Nodo de Aragón, for its support in the development of this study.

\section{References}

I. Infante C, Rubio-Colavida JM: La prevalencia del consumo de tabaco en España. Adicciones 2004, I 6(Supl. 2):59-74.

2. Instituto Nacional de Estadística: [http://www.ine.es].

3. Silagy C, Stead LF: Physician advice for smoking cessation (Cochrane Review). In En: The Cochrane Library Issue 3 Oxford: Update Software; 2001.

4. Fiore MC, Bailey WC, Cohen SC: Smoking cessation. In Treating Tobacco Use and Dependende: Clinical Practice Guideline Rockville, MD: US Dept of Health and Human Serveces, Public Health Service; 2000.

5. Cinciripini PM, Lapitsky LG, Wallfisch A, Mace R, Nezami E: An evaluation of a multicomponent treatment program involving scheduled smoking and relapse prevention procedures: Initial findings. Addictive Behaviours 1994, 19:13-22.

6. Vellisco García A, Álvarez Gutiérrez FJ, Elías Hernández T, Medina Gallardo JF, Alcantarilla Reina D, Boreloy Sánchez C, Castillo Gómez J: Resultados de un programa psicofarmacológico de deshabituación tabáquica (parches y psicoterapia) tras doce meses de seguimiento. Prev Tab 2003, 5(1):5-10.

7. Silagy C: Nicotine replacement therapy for smoking cessation (Cochrane Review). In The Cochrane Library, n 2 Oxford: Update Software; 2001.

8. Sachs DPL, Säwe U, Leischow SJ: Effectiveness of a 16-hour transdermal nicotina patch in a medical practice setting, without intensive group counseling. Arch Intern Med 1993, 153: $188 \mid-1890$.

9. Tonnesen P, Paoletti P, Gustavsson G, Russell MA, Saracci R, Gulsvik A, Rickjen B, Sawe U: Higher dosage nicotine patches increase one-year smoking cessation rates: results from the European CEASE-trial. Eur Respir 1999, 13:238-46.

10. Shiffman S, Dresler CM, Hajek P, Gilburt SJA, Target DA, Strahs KR: Efficacy of a nicotine lozenge for smoking cessation. Arch Intern Med 2002, 162: I 267-1276.

II. Puska $P$, Korhonen $H$, Vartiainen $E$ : Combined use of nicotine patch and gum compared with gum alone in smoking cessation: a clinical trial in North Karelia. Tob Control 1995, 4:23I-5.

12. Hayford KE, Patten CA, Rummans TA, Schroeder DR, Offord KP, Croghan IT: Efficacy of bupropion for smoking cessation in smokers with a former history of major depression or alcoholism. Br J Psychiatry 1999, 174: 173-8.

13. Holm KJ, Spencer CM: Bupropion : Review of its use on the treatment of smoking cessation. Drugs 2000, 59:1007-26.

14. Arnone D: Review of the use of topiramate for treatment of psychiatric disorders. Ann Gen Psychiatry 2005, 4:5.

15. Johnson BA, Ait Daoud N, Bowden CL, Di Clemente CC, Roache JD, Lawson K, Javors M, Ma JZ: Oral topiramate for treatment of alcohol dependence: a randomized controlled trial. Lancet 2003, 36 I: I667-85.

16. Johnson BA, Ait Daoud N, Akhtar FZ, Javors MA: Use of oral topiramate to promote smoking abstinence among alcoholdependent smokers: a randomized controlled trial. Arch Int Med 2005, 165:1600-05.

17. Khazaal Y, Cornuz J, Bilancioni R, Zullino DF: Topiramate for smoking cessation. Psychiatry Clin Neurosci 2006, 60:384-88. 
18. Sofouglu M, Poling J, Mouratidis M, Kosten T: Effect of topiramate in combination with intravenous nicotine in abstinent overnight smokers. Psychopharmacology 2006, I 84:645-5I.

19. García Campayo J, Sobradiel N: Tabaco y psiquiatría (Tobacco and psychiatry). Barcelona: Edikamed; 2008.

20. Cooney JL, Stevens TA, Cooney NL: Comorbility of nicotine dependence with psychiatric and substance-use disorders. In Dual diagnosis and treatment Edited by: Kranzler HR, Rounsaville BJ. New York: Marcel Deker; 1998:223-6I.

21. Covey LS: Tobacco cessation among patients with depression. Prim Care 1999, 26:691-706.

22. Conde V, Escribá JA, Izquierdo J: Evaluación estadística y adaptación castellana de la escala autoaplicada para la depresión de Zung. Arch Neurobiol 1970, 33:28I-303.

23. Prochaska JO, Diclemente CC: Stages and processes of selfchange of smoking: toward an integrative model of change. J Consult Clin Psychol 1983, 5 I:390.

24. Ferrando L, Franco A, Bobes J: MINI International Neuropsychiatric Interview. Instituto IAP, Madrid 1998.

25. Hughes JR, Hatsukami DK: Signs and symptoms of tobacco withdrawal. Arch Gen Psychiatr 1986, 43:289-294.

26. Jarvis M, Russell MAH, Salojee Y: Expired air carbon monoxide. A simple breath test for tobacco smoke intake. $\mathrm{Br} M e d / 1980$ 28 I:484-5.

27. Barrueco M, Jiménez C, Palomo L, Torrecilla M, Romero P, Riesco JA: Abstinencia puntual y continuada con el tratamiento farmacológico del tabaquismo en la práctica clínica. Med Clin 2004, I 23:652-6.

28. Domingo-Salvany A, Regidor E, Alonso J, Alvarez-Dardet C: Una propuesta de medida de la clase social. Aten Primaria 2000, 25:350-63.

29. Becoña E, Vazquez FL: The Fagerström test for Nicotine Dependence in a Spanish sample. Psychological Reports 1998 , 83(3 Pt2): |455-|458

30. Spielberger CD, Gorsuch RL, Lushene RE: Cuestionario de ansiedad estado - rasgo. TEA Madrid 1968.

31. Rubio G, Montero I, Jáuregui J, Martínez ML, Álvarez S, Marín JJ: Validación de la escala de impulsividad de Plutchik en población española. Arch Neurobiol 1999, 6 I:223-232.

32. Vellisco A, Alvarez FJ, Elias T: Resultados de un programa psicofarmacológico de deshabituación tabáquica tras 12 meses de seguimiento. Prev Tab 2003, 5:5-10.

33. Gordis L: Epidemiology. Philadelphia: Saunders; 1996

34. Littell JH, Girvin H: Stages of change. A critique Behav Modif 2002 26:223-73.

\section{Pre-publication history}

The pre-publication history for this paper can be accessed here:

http://www.biomedcentral.com/1471-2296/9/28/prepub
Publish with BioMed Central and every scientist can read your work free of charge

"BioMed Central will be the most significant development for disseminating the results of biomedical research in our lifetime. "

Sir Paul Nurse, Cancer Research UK

Your research papers will be:

- available free of charge to the entire biomedical community

- peer reviewed and published immediately upon acceptance

- cited in PubMed and archived on PubMed Central

- yours - you keep the copyright
BioMedcentral 